\title{
AUTOMATING OCCUPATIONAL PROTECTION RECORDS SYSTEMS
}

M. Lyon

J. B. Martin

October 1991

\author{
Presented at the \\ Current Topics in Occupational \\ Health Conference \\ October 29 - November 1, 1991 \\ Richland, Washington
}

Work supported by

the U.S. Department of Energy

under Contract DE-AC06-76RLO 1830

\author{
Pacific Northwest Laboratory \\ Richland, Washington 99352
}

\section{DISCLAIMER}

\begin{abstract}
This report was prepared as an account of work sponsored by an agency of the United States Government. Neither the United States Government nor any agency thereof, nor any of their employees, makes any warranty, express or implied, or assumes any legal liability or responsibility for the accuracy, completeness, or usefulness of any information, apparatus, product, or process disclosed, or represents that its use would not infringe privately owned rights. Reference herein to any specific commercial product, process, or service by trade name, trademark, manufacturer, or otherwise does not necessarily constitute or imply its endorsement, recommendation, or favoring by the United States Government or any agency thereof. The views and opinions of authors expressed herein do not necessarily state or reflect those of the United States Government or any agency thereof.
\end{abstract}


ABSTRACT

Occupational protection records have traditionally been generated by field and laboratory personnel, assembled into files in the safety office, and eventually stored in a warehouse or other facility. Until recently, these records have been primarily paper copies, often handwritten. Sometimes, the paper is microfilmed for storage. However, electronic records are beginning to replace these traditional methods. The purpose of this paper is to provide guidance for making the transition to automated record keeping and retrieval using modern computer equipment.

This paper describes the types of records most readily converted to electronic record keeping and a methodology for implementing an automated record system. The process of conversion is based on a requirements analysis to assess program needs and a high level of user involvement during the development. The importance of indexing the hard copy records for easy retrieval is also discussed. The concept of linkage bet:yeen related records and its importance relative to reporting, research, and litigation will be addressed.

\section{INTRODUCTION}

Occupational protection records systems maintain records of exposure of personnel to hazardous materials and conditions in the workplace, such as chemicals, ionizing and nonionizing radiation, carcinogens, laser light, noise, etc. In addition to protection of 
workers, some of the reasons for maintaining these records include the evaluation of the effectiveness of the protection program, the demonstration of compliance with regulations and requirements, and defense of the program from unwarranted litigation. The goal of any occupational protection records system should be the compilation of complete and accurate individual exposure histories with substantial. documentation. Many of the records maintained by these systems can beconverted to electronic records. Most exposure records can be computerized such that a complete occupational health record can be readily accessed by those with a need to know. Many monitoring results can be computerized and linked to exposures. A completely paperless system is not practical because many computerized records may need to be backed up with hard copy documentation. However, the hard copy records can be indexed into a computer-assisted retrieval (CAR) system for ready access. Which records are computerized will depend upon the importance placed on the particular data, the need to retain it, the availability required for the data, ant, often, the size and cost restrictions of the database.

Experience has shown that there are many computer systems that just do not work very well or meet the needs of the users. At the Pacific Northwest Laboratory $(P N L){ }^{a}$ the Hanford Occupational Radiological Exposure (ORE) System is being redeveloped. When we first

a The Pacific Northwest Laboratory is operated for the U.S. Department of Energy by Battelle Memorial Institute under contract DE ACO6-76RLO 1830 
investigated how to go about doing this, we found that some groups, when automating or redeveloping an existing automated system, first buy a computer system and software. They then contact the information systems department and tell them they need a records system. The information systems people go off, design and program a system, and then give, the requestors a system that just does not work well or meet their needs.

To avoid this, the development, or redevelopment, of a computer system must follow a system design life cycle approach as illustrated in Figure 1. The life cycle starts with a requirements analys is in which user requirements and the budget and schedule are examined. The requirements document lists in detail what the system will contain and what it will do. After the requirements analysis is completed, an alternatives analysis is performed. This analysis will determine the hardware and software that will best support the requirements determined during the requirements analysis and is affordable. During the alternatives analysis, some preliminary design effort can be performed. During the detailed design/construction phase, based on the requirements study, the detailed design, programming, and testing proceed until the system is ready for implementation. The implementation phase includes training of users, a test run of the completed system, and final acceptance of the system by the user. The system is then put into production.

SYSTEM DESIGN LIFE CYCLE

Requirements Analysis Phase 
The requirements analysis is the most important effort of the project. All of the rest of the project will be based on it. This effort must have a high level of user involvement by the steering committee, user interviews, and user feedback (See Figure 2). During this phase the programmers, who may be from outside the record-keeping department, should learn and understand the business that the system supports by reviewing existing procedures, making direct observations, and performing data flow analysis. The requirements document, resulting from the analysis, should be carefully reviewed and approved by the users. In general, any change in the requirements at a later stage will affect the project schedule and budget.

There are several objectives, at a minimum, that the requirements analysis should meet. First, critical data elements that will be - included in the system should be identified and described. Then, all of the system processing activities must be identified and described. Current and future storage and processing volume must also be assessed. This assessment will be a determining factor in the type of hardware and software that will be acceptable to consider in the alternatives analysis.

System strategies for record retention, access control, security, and data integrity must be determined. Each record in the protection program should have a retention requirement - how long and in what form - determined. Because much of the data in these systems involve information on people they are often sensitive. Therefore, the strategy for controlling access to the records must be considered. Again, due to 
the sensitive nature of many of the records, security needs must be assessed. The requirement for stringent access control and security measures may exclude certain types of computer systems. System strategies for assuring data integrity is a vital consideration; eliminating incorrect and invalid data from the system is crucial and the basis for how this is to be done should be included at this stage. Finally, a verifiable model of the system that correlates with the business area it represents should be built. This model should be easily understandable to the users who are often not versed in the technical aspects of certain types of computer system modeling and would have to take involved training to understand the concepts. Data flow models are usually relatively simple to understand and users can quickly learn the meanings of the graphical symbols.

A number of tools should be used in the requirements analysis. A user's oversight committee should be col.tinuously involved during the complete life cycle and should have approval of all changes after the requirements analysis is completed. The committee should include people who can make decisions rapidly to prevent cost and schedule problems. It must also include people who will eventually use the system. Second, if there a records system in place, even if it only involves paper stored in filing cabinets, any operating procedures and existing documents should be used. Along with direct observation of the existing system, these procedures will help the software designers to understand the business they will be dealing with. User interviews by the designers are an important part of the analysis. Third, a data flow 
analysis should be performed by the designers, including walk-throughs of the business processes with the users. The input for the data flow analysis consisis of 1) what processes make up the system, 2) what data is used in each process (inputs and outputs), and 3) what data is stored and where it is stored (e.g., in the database or a file cabinet). Then, the processes should be iteratively decomposed to arrive at the necessary level of detail to assure a complete understanding of the system. The model can then be documented using data flow diagrams. The users should then review and correct the data flow diagrams. At this stage, a high-level data dictionary should be developed to name the data elements to be stored and manipulated in the database. Such a dictionary allows the users and the designers to speak a common 1anguage.

The final pri 'uct of the requirements analysis is the requirements document. The document should contain a general summary, including a section on background information the new system's purpose, its goals, and a documentation of the current environment. The basic requirements for the new system must also be included in the requirements document; this information should include the system inputs and outputs, data characteristics, and the processes involved. The system inputs and outputs should describe what data goes into the system, how and where it is to be stored, and what reports or other output is required. The data characteristics should describe what form the data is kept in, such as the units of measurement to be used. 
Other items also need consideration and should be included in the requirements document: 1) resource constraints, i.e., how much money and how many people are available for the development project, 2) security constraints, i.e., how stringent the data protection must be, 3 ) regulatory constraints, i.e., whether governmental or facility regulations are involved and if they are being met, 4) assumptions, due to lack of absolute data, 5) User interfaces, including who, how many, and for what purpose, 6) system interfaces, 7) scheduling, i.e, how long will it take to get the new system into production, 8) data administration, 9) test and acceptance criteria, 10) portability among different hardware and software with a minimum of modifications, 11) documentation (complete documentation of the system is vital), 12) training for all users, 13) options, i.e., what options were considered where certain decisions were made, 14) reliability and recovery, i.e., how vital is the data to continued operation of the facility and how reliable must the system be and how rapidly must it be recovered in case of disaster, 15) responsibilities for aspects of the development, 16) conversion of existing system to the new hardware and software.

\section{Alternatives Analysis}

The alternatives analysis follows the requirements analysis and must be based on the requirements. The steps involved in this analysis include identifying hardware and software alternatives and then selecting several of the most promising alternatives. Sometimes, the only options may be a facility mainframe or a personal computer based 
system. However, there are times when the purchase of a new dedicated system may be justified either by requirements or cost. The next step is to determine the life cycle costs for each selected alternative. The benefits and drawbacks associated with each must then be identified. Finally, after analysis oi the data, the most effective course of action is determined. The analysis shuid be documented and the selection justified.

\section{System Design}

During the preliminary design phase certain tasks should be accomplished. A project management plan detailed down to a fairly small task level should be completed. From this plan a final estimate of the cost should be calculated. In addition, acceptance criteria, based on the requirements document, and a quality assurance plan should be generated.

The detailed design phase includes generation of the written design specifications. These specifications should be walked through with the users to assure they meet their requirements. There should be a detailed design document produced that is approved by the customer. In addition, a test plan, based on the acceptance criteria should be developed.

Following the detailed design phase the programming of the system will take place.

System Testing 
During the programming, the design team should perform module testing. Each individual module should be tested as it is completed with the user involved in the testing. Then, the modules should be integrated and tested again with a test run after each module is added. As flaws are found they are corrected and retested until the system functions as designed.

Implementation

The implementation phase includes the development of a user manual, the training of user personne?, and a complete test run by the user. The training of user personnel may start during earlier phases, particularly those that need in-depth knowledge of the operation of the system. After the test run, the user must verify that all of the requirements have been met and that all results sre correct. Some hand calculations may have to be made to assure the computer programs have correctly handled any calculations. If redeveloping an existing system; a parallel run with the old system should be made and the results compared.

When the system operates as the users want it to it can then be accepted and put into production.

\section{OTHER CONSIDERATIONS}

An important consideration is the method for storing hard copy records that must be retained. They can be maintained as paper records and stored in filing cabinets or in storage facilities. The paper can 
be converted to microfilm or microfiche. A new storage method, laser optical disk, appears to have considerable promise fur ready access and retrieval. As the paper is reduced to digital form, it can be transmitted in electronic form and viewed on computer monitors.

Another consideration is how to have ready access to hard-copy documents. If there are large numbers of documents, consideration should be given to indexing them into a computer assisted retrieval (CAR) system. Specific documents can be indexed with the storage location such they can be retrieved from millions of documents in minutes.

Finally, documents should be linked such that all related information can be retrieved. For instance, in the case of an incident, all exposures as well as monitoring results for the job, calibration records for the monitoring instruments, job safety specifications, the training records of the individuals involved and the protection personnel assigned, any assessments of exposure, incident reports, etc., should be readily available and accessible. In the case of unwarranted litigation, experience has shown that providing complete records to the court can often lead to a successful defense. On the other hand, poor and incomplete records usually results in a judgement or expensive settlement for the plaintiff.

\section{CONCLUSION}

Tile development of an automated protection records system is a very involved process. The two most important aspects of a successfur 
project are the completion of an accurate and complete requirements analysis and highly active user involvement. If the requirements analysis is done right and the users assure the designers stick to the requirements, a responsive and useable system should result. 
FIGURES

Figure 1. Computer System Software Development Life Cycle

Figure 2. Computer System Software Development Requirements Analys is Phase 


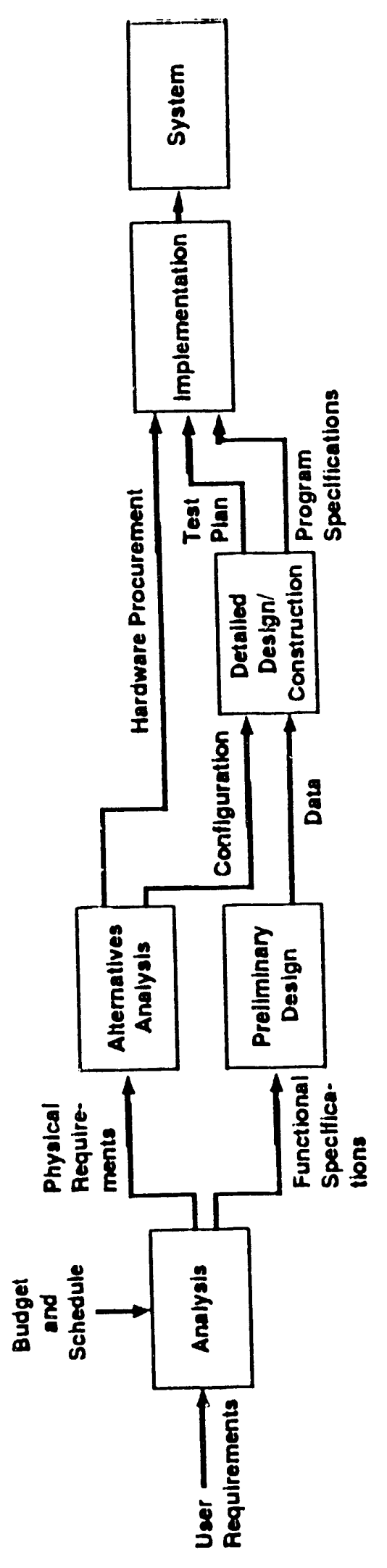

సู 


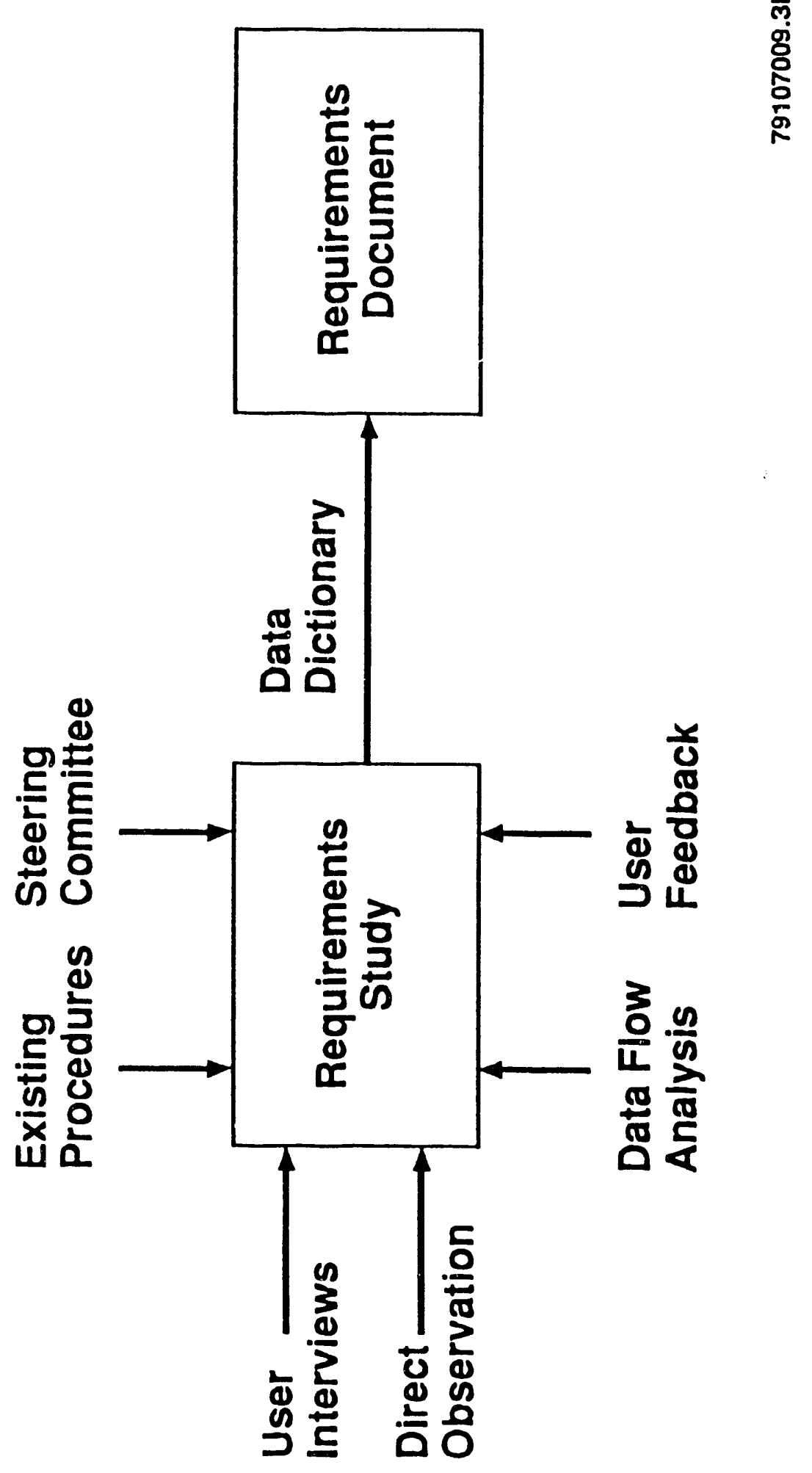



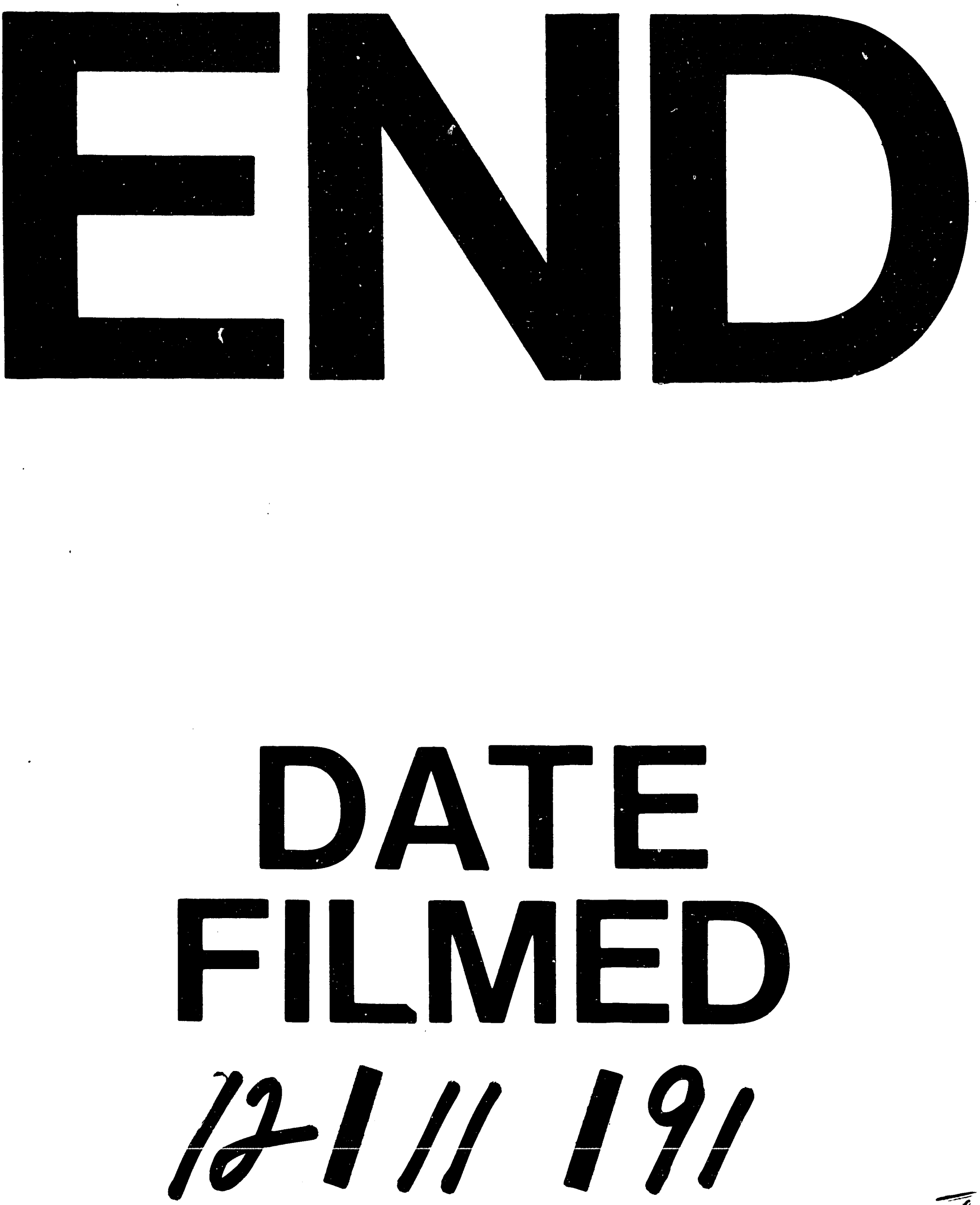

$\bar{I}$. 
